\title{
The mechanism of miR-143 inducing apoptosis of liver carcinoma cells through regulation of the NF-kB pathway
}

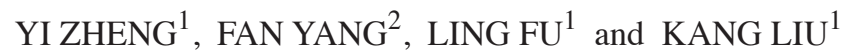 \\ ${ }^{1}$ Department of Medical Oncology, Affiliated Hospital of Weifang Medical University; ${ }^{2}$ Department of \\ Traditional Chinese Medicine, Weifang Hi-tech Zone People's Hospital, Weifang, Shandong 261000, P.R. China
}

Received July 24, 2017; Accepted December 1, 2017

DOI: $10.3892 / \mathrm{ol} .2018 .8486$

\begin{abstract}
Primary hepatic carcinoma is a common malignant tumor with poor treatment efficacy. The effect and mechanism of miR-143 in apoptosis of liver carcinoma cells were investigated in the present study. In vitro transfection of liver carcinoma SMMC-7721 cells was performed using artificially synthesized miR-143 mimics. The proliferation of liver carcinoma cells that were treated was detected by MTT assay. Liver carcinoma cells were then stained using the Annexin V-FITC/PI method, and the apoptosis of stained liver carcinoma cells was measured using a flow cytometer. The relative mRNA expression of NF- $\mathrm{NB}$ p65 in the intervention and control groups was assayed using reverse transcription-quantitative polymerase chain reaction, and the protein expression of $\mathrm{NF}-\kappa \mathrm{B}$ p 65 was detected using western blot analysis. The results showed that, in the intervention group, the proliferation rate of cells transfected using miR-143 mimics was significantly lower than that in the control group, the number of apoptotic SMMC-7721 cells in the intervention group increased, and the protein expression of NF- $\kappa$ B p65 was decreased. Thus, miR-143 may downregulate the protein expression of $\mathrm{NF}-\kappa \mathrm{B}$ p 65 , thereby triggering the NF- $\mathrm{NB}$ signaling transduction pathway inducing apoptosis of liver carcinoma cells.
\end{abstract}

\section{Introduction}

Primary hepatic carcinoma (PHC) is a common malignant tumor, and its incidence rate ranks 6th in the world (1). Among nearly 60 million patients who succumb to PHC each year, patients from the developing countries account for over $80 \%$, of which Chinese patients account for $55 \%(2,3)$. At present, the treatment methods of PHC mainly include the surgical resection, chemotherapy and radiotherapy, albeit with poor efficacy, resulting in frequent side-effects. Biotherapy, with

Correspondence to: Dr Yi Zheng, Department of Medical Oncology, Affiliated Hospital of Weifang Medical University, 2428 Yuhe Road, Kuiwen, Weifang, Shandong 261000, P.R. China E-mail: zhengyiz10304@126.com

Key words: miR-143, NF-кB, cell apoptosis advantages such as high efficiency, slight side effects and precision, may be able to serve as another effective method for the treatment of PHC (4).

MicroRNAs (miRNAs or miRs), conserved in evolution, non-coding, small RNA molecules 20 and 25 bp in length are characterized by the regulation of the genetic expression at the level of translation $(5,6)$. The results of some experiments showed that miR-143 is expressed at a low level in many malignant tumors, such as colorectal (7), lung (8), esophageal (9), and breast (10) cancers. However, few studies have focused on the correlation between miR-143 and the occurrence and development of liver cancer, and the effect of miR-143 on the mechanism is also still unknown. In this study, artificially synthesized miR-143 mimics were used to transfect the liver carcinoma SMMC-7721 cell line to observe the effect of miR-143 on the genetic and protein expression of liver carcinoma cells, and we inferred the potential action mechanism in the development and occurrence of liver carcinoma.

\section{Materials and methods}

Materials. The materials obtained for the study were: SMMC-7721 human liver carcinoma cell line (Institute of Cell Biology, Shanghai Institutes for Biological Sciences, Chinese Academy of Sciences, Shanghai, China); cell apoptosis detection kit (Run-well Industrial Co., Ltd., Shanghai, China); Lipofectamine ${ }^{\mathrm{TM}} 2000$ (Biotsith Bioscience Co., Ltd., Suzhou, China); miR-143 mimics (Miaoling Bioscience and Technology Co., Ltd., Wuhan, China); methyl thiazolyl tetrazolium (MTT; Beijing Huamaike Biotechnology Co., Ltd., Beijing, China); dimethyl sulfoxide (DMSO; Tideradar Science and Technology Co., Ltd., Beijing, China); TRIGene kit (Abbiotechnology, Inc., Guangzhou, China); reverse transcription kit (GeneCopoeia, Rockville, MD, USA); cell total protein extraction kit (Biogenro Biotechnology Co. Ltd., Beijing, China); NF- $\kappa$ B p65 Trans AM ${ }^{\mathrm{TM}}$ enzyme-linked immunosorbent assay (ELISA) kit (Jiamay Biotech Co., Ltd., Beijing, China). Primary and secondary antibodies, all from (Cell Signaling Technology, Danvers, MA, USA).

Cell culture and transfection. Total cell culture medium was prepared as follows: Dulbecco's modified Eagle's medium $($ DMEM $)+10 \%$ fetal bovine serum $($ FBS $)+1 \%$ double-antibody. SMMC-7721 liver carcinoma cell line was cultured in 
an incubator $\left(37^{\circ} \mathrm{C}, 5 \% \mathrm{CO}_{2}\right)$, and the following transfection experiments were prepared according to the instructions in Lipofectamine $^{\mathrm{TM}}$ 2000, in which miR-143 mimics were transfected into the SMMC-7721 liver carcinoma cell line, and the transfected cells were divided into the mimics and negative control groups.

Detection of cell proliferation through MTT experiments. Under the microscope (Olympus Corporation, Tokyo, Japan), we observed cell growth. After being digested sufficiently and the cells were counted, the cell density was adjusted to $5 \times 10^{5} / \mathrm{ml}$, and the cells were inoculated into a 96-well plate (100 $\mu \mathrm{l} /$ well). These cells were cultured for 24,48 and $72 \mathrm{~h}$, and the prepared $20 \mu \mathrm{l}$ MTT solution was added into the plate in the dark. Then, the plate was placed into an incubator for $4 \mathrm{~h}$ at $37^{\circ} \mathrm{C}$, and the supernatant was discarded. A $150 \mathrm{ml}$ DMSO solution was added into each well followed by vibration on a shaker, and after approximately $10 \mathrm{~min}$, the crystal-like substance was totally dissolved in DMSO solution. A Sunrise microplate reader (Tecan Group Ltd., Männedorf, Switzerland) was used to detect the optical density of each well at the wavelength of $490 \mathrm{~nm}\left(\mathrm{OD}_{490}\right)$, and the average of OD values was taken as the result.

Detection of cell apoptosis. The SMMC-7721 liver carcinoma cell line was inoculated into the 6-well plate, and transfection intervention was performed for cells in the logarithmic phase (procedures were the same as mentioned earlier). After $48 \mathrm{~h}$ of transfection, the cells in the mimics and negative control groups were digested with trypsin, and collected into the centrifuge tubes. The tubes were centrifuged for $5 \mathrm{~min}$ at $8,600 \times \mathrm{g}$ and the supernatant was discarded. The cells were mixed with the pre-cooled phosphate buffer, and the procedure was repeated 3 times followed by resuspension of cells to prepare the cell suspension at a density of $5 \times 10^{5} / \mathrm{ml}$, in which we extracted $1 \mathrm{ml}$ suspension for centrifugation and then the supernatant was discarded. In the sediment, $500 \mu 1$ binding buffer, $5 \mu \mathrm{l}$ Annexin V-FITC and $10 \mu \mathrm{l}$ propidium iodide (PI) were sequentially added. The suspension was then incubated in the dark for $10 \mathrm{~min}$. A flow cytometer (Attune NxT; Thermo Fisher Scientific, Inc., Waltham, MA, USA) was used to detect cell apoptosis in the mimics and negative control groups.

Detection of $m R N A$ expression using reverse transcription-quantitative polymerase chain reaction ( $R T$-qPCR). According to the procedures of instructions in the TRIGene kit, the total RNA was extracted from the mimics and negative control groups, respectively, and a spectrophotometer (Bio-Rad Laboratories, Inc., Hercules, CA, USA) was used to detect the concentration and purification of total RNAs, in which A260/A280 values were between 1.8 and 2.0. In accordance with the instructions of reverse transcription kit (RevertAid Fist Strand cDNA Synthesis kit, K1622; Thermo Fisher Scientific, Inc., Waltham, MA, USA), and the primer sequences were produced by Shanghai JiRan Biotechnology Co., Ltd. (Shanghai, China) (Table I). The reverse transcription was performed for preparation of cDNA in $20 \mu \mathrm{l}$ reaction system that was placed on the RT-PCR apparatus.

The $25 \mu \mathrm{l}$ reaction system was prepared as per the protocol of the quantitative PCR kit (2X RealStar Green Power Mixture,
Table I. Primer sequence of NF-кB p65.

\begin{tabular}{lc}
\hline Genes & Primers \\
\hline$N F-\kappa B p 65$ & F: 5'-TACCCTGAGGCTATAACTC-3' \\
& R: 5'-GACACTTGATAAGGCTTTG-3' \\
GAPDH & F: 5'-TGGGTGTGAACCACGAGAA-3' \\
& R: 5'-GGCATGGACTGTGGTCATGA-3'
\end{tabular}

F, forward; R, reverse.

A311; GenStar Biosolutions Co., Ltd., Beijing, China), and the reaction conditions were set as follows: denaturation at $95^{\circ} \mathrm{C}$ for $10 \mathrm{~min}$, annealing at $95^{\circ} \mathrm{C}$ for $30 \mathrm{sec}$, extension at $59.4^{\circ} \mathrm{C}$ for $30 \mathrm{sec}$, for a total of 40 cycles, with a final extension at $95^{\circ} \mathrm{C}$ for $15 \mathrm{sec}$, and cooling down to $65^{\circ} \mathrm{C}$. GAPDH served as an internal reference, and the quantitative value was used in the automatic calculation of the relative mRNA expression of NF-кB p65 using RT-PCR apparatus.

Detection of the protein expression via western blot analysis. Total proteins from the mimics and negative control groups were extracted as per the protocol of the cell total protein extraction kit, and the concentration of extracted proteins was assayed. The proteins were preserved at $-70^{\circ} \mathrm{C}$ for later use. Gel at different concentrations was prepared for SDS-PAGE, and the position of NF- $\kappa \mathrm{B}$ p 65 was verified with the reference marker stripe. A gel of appropriate size was cut for $30 \mathrm{~min}$ of membrane transferring, and blocked using $5 \%$ bovine serum albumin (BSA) for $1 \mathrm{~h}$. The mouse anti-human NF- $\kappa \mathrm{B}$ and GAPDH primary monoclonal antibody (dilution, 1:1,000; cat. nos. 6956 and 97166) were added onto the membrane for incubation overnight at $4^{\circ} \mathrm{C}$. Tris-buffered saline and Tween-20 (TBST) was used to wash the polyvinylidene fluoride (PVDF) membrane 3 times (5 min/time). The membrane was incubated at room temperature using the horse anti-mouse HRP secondary polyclonal antibody (dilution, 1:2,000; cat. no. 7076) for $1 \mathrm{~h}$, and TBST was used to wash the PVDF membrane 3 times ( $5 \mathrm{~min} / \mathrm{time}$ ). Electrochemiluminescence (ECL) color-development solution was added onto the membrane for exposure in the dark, and the ChemiDoc ${ }^{\mathrm{TM}} \mathrm{MP}$ imaging system was used for scanning. Images imported into the system were analyzed using ImageJ professional image analytic software, and the optical density was recorded.

Assay of $N F-\kappa B$ activity. The NF- $\kappa \mathrm{B}$ p65 TransAM ${ }^{\mathrm{TM}}$ ELISA kit was used for assay of NF- $\kappa \mathrm{B}$ activity in SMMC-7721 cells. The cell proteins were extracted from the mimics and negative control groups, and then added into the 96-well plate containing oligonucleotides in the homologous region of $\mathrm{NF}-\kappa \mathrm{B}$. The plate was agitated slightly and incubated at room temperature for $1 \mathrm{~h}$ followed by washing using distilled water 3 or 4 times. Thereafter, the antibody of $N F-\kappa B$ was added for $1 \mathrm{~h}$ of incubation at room temperature. Again, the plate was washed 3 or 4 times using distilled water. Horse anti-mouse HRP secondary polyclonal antibody (dilution, 1:1,000; cat. no. 7076) was added and the proteins were incubated for $1 \mathrm{~h}$ at room temperature followed by the color development 


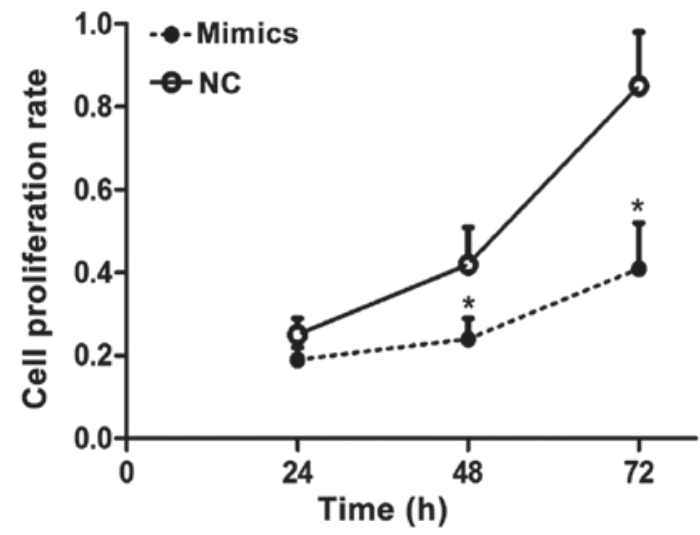

Figure 1. Cell proliferation rates in the mimics and negative control groups. Compared with the negative control group, ${ }^{*} \mathrm{p}<0.05$.
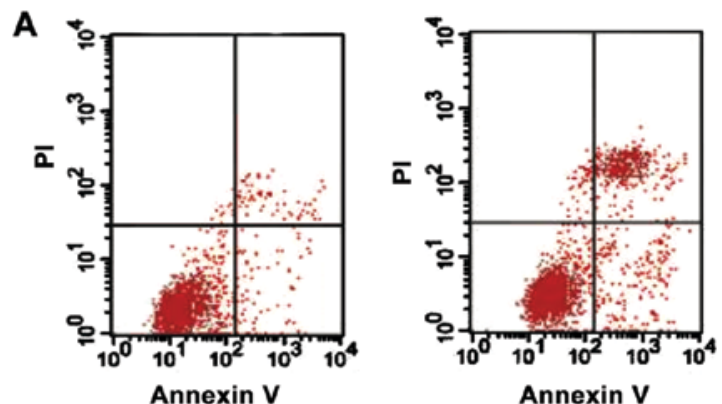

B

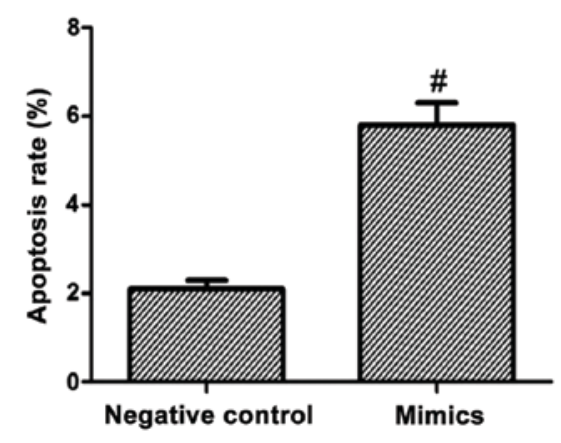

Figure 2. Changes in the apoptotic rate after cells were transfected using oligonucleotides. Compared with the negative control group, ${ }^{\#} \mathrm{p}<0.05$.

reaction and terminating reaction. The Sunrise microplate reader was used to detect the activity of NF- $\mathrm{\kappa B}$ at a wavelength of $450 \mathrm{~nm}$.

Statistical analysis. Statistical Product and Service Solutions (SPSS) 16.0 (SPSS, Inc., Chicago, IL, USA) software was used for statistical analysis of the data. Measurement data are presented as mean \pm standard deviation, and one-way analysis of variance and paired t-test were applied in the analysis in comparison between groups. $\mathrm{P}<0.05$ was considered to indicate a statistically significant difference.

\section{Results}

Results of the MTT assay. Results of the MTT assay for proliferation of liver carcinoma cells showed that after
Table II. Protein expression of NF- $\mathrm{KB}$ p65 in the negative control and mimics groups (mean $\pm \mathrm{SD}$ ).

\begin{tabular}{lcc}
\hline Variable & Negative control group & Mimics group \\
\hline NF- $\mathrm{kB} \mathrm{p65}$ & $1.1582 \pm 0.0319$ & $0.4376 \pm 0.0428^{\mathrm{a}}$ \\
\hline Compared with the negative control group, ${ }^{\mathrm{a}} \mathrm{p}<0.05$. \\
\hline
\end{tabular}

Table III. NF- $\kappa B$ activity assay.

\begin{tabular}{lccc}
\hline Group & NF- $\kappa B$ activity & F-value & P-value \\
\hline Negative control & $0.51 \pm 0.05$ & 341.374 & $<0.01$ \\
miR-143 mimics & $0.22 \pm 0.04^{\mathrm{a}}$ & & \\
\hline
\end{tabular}

Compared with the negative control group, ${ }^{\mathrm{a}} \mathrm{p}<0.01$.

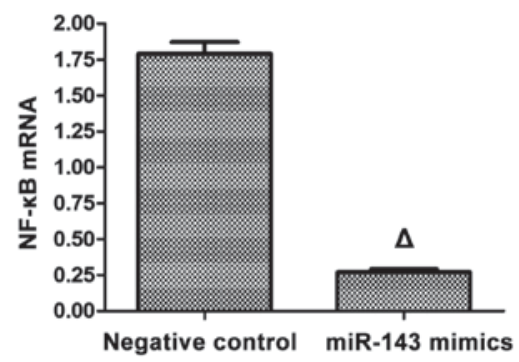

Figure 3. mRNA expression of NF- $\mathrm{\kappa B}$ in the mimics and the negative control groups. Compared with the negative control group, ${ }^{\Delta} \mathrm{p}<0.05$.

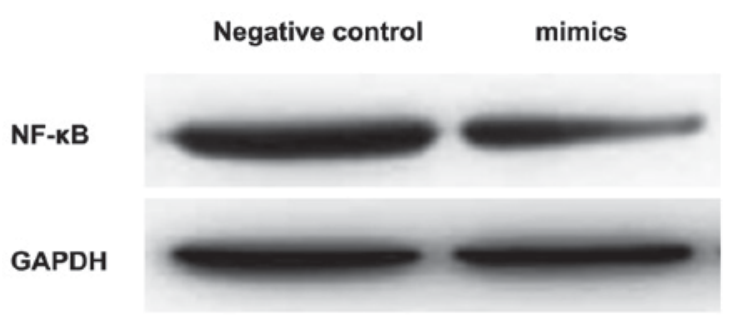

Figure 4. Protein expression of NF-кB in the mimics and negative control groups.

SMMC-7721 liver carcinoma cell line was transfected by mimics for 24,48 and $72 \mathrm{~h}$, the cell proliferation rate in the negative control group was significantly higher than that in the mimics group, and the difference had statistical significance $(\mathrm{p}<0.05)$, suggesting that miR-143 can obviously inhibit the proliferation of liver carcinoma cells (Fig. 1).

Results of cell apoptosis experiment. After the SMMC-7721 liver carcinoma cell line was transfected by mimics for $48 \mathrm{~h}$, cell apoptotic rates of the mimics and negative control groups were detected using a flow cytometer. The results showed that the cell apoptotic rate in the mimics group was significantly higher than that in the negative control group, with a statistically significant difference ( $<<0.05 ;$ Fig. 2$)$. 
Detection of $m R N A$ expression of $N F-\kappa B$ using $R T-q P C R$. RT-qPCR was applied in the detection of mRNA expression of NF- $\kappa \mathrm{B}$, and the results showed that after the SMMC-7721 liver carcinoma cell line was transfected with mimics for $48 \mathrm{~h}$, the mRNA expression of NF- $\kappa \mathrm{B}$ in the mimics group was significantly lower than that in the negative control group with a statistically significant difference $(\mathrm{p}<0.05$; Fig. 3$)$.

Detection of the expression of $N F-\kappa B$ p 65 via western blot analysis. Western blot analysis revealed that the protein expression level of NF- $\kappa \mathrm{B}$ p65 in the intervention group was significantly lower than that in the control group, and the difference was of statistical significance $(\mathrm{p}<0.05$; Table II and Fig. 4).

Result of $N F-\kappa B$ activity assay. After the cells were transfected with miR-143 mimics for $48 \mathrm{~h}$, the NF- $\kappa \mathrm{B}$ activity in the SMMC-7721 liver carcinoma cell line was $0.22 \pm 0.04$, which was significantly lower than that in the control group $(\mathrm{p}<0.01$; Table III).

\section{Discussion}

Liver carcinoma is usually characterized by high malignancy, and due to the difficulties in diagnosis at early or middle stage, patients with liver carcinoma are usually diagnosed at the late stage, making it difficult for radical resection. Consequently, conventional surgeries, chemotherapy and radiotherapy have been greatly limited in clinical practice as treatment for liver carcinoma (11). In recent years, the newly emerged biotherapy has been viewed as a new method for the treatment of malignant tumors, and, therefore, searching for the new targets is of great clinical and practical significance in the treatment of malignant tumors. In humans, there are a variety of oncogenes and anti-oncogenes, which can act alone, or together to form a network system to perform a synergistic effect, thereby promoting or inhibiting the occurrence and development of tumors (12). miRNAs, the important genetic regulatory factors in humans, have been reported to exert regulatory effects on the occurrence and development of liver carcinoma (13). Nevertheless, the mechanism of miR-143 involved in the development of liver carcinoma remains to be determined (14). Thus, in this study, we preliminarily investigated the mechanism how miR-143 affects the development of liver carcinoma. miR-143 exists in various cells in humans, and miR-143 has been reported to have lower expression levels in many kinds of tumor cells, such as cervical (15) and prostate (16) cancers. Currently, there are few studies reporting the correlations between miR-143 and the occurrence and development of liver carcinoma. In addition, there is controversy regarding this correlation in the published literature. Some scholars have found that miR-143 is expressed at low levels in liver carcinoma tissues (17). However, the findings of other authors indicated that miR-143 is highly expressed in liver carcinoma, and acts as an anti-oncogene to effectively suppress the invasion and metastasis of liver carcinoma cells (18).

In this study, we performed an MTT assay after the SMMC-7721 liver carcinoma cell line was transfected with miR-143 mimics, and found that the proliferation rate of liver carcinoma cells in the mimics group was significantly lower than that in the negative control group, and the difference was of statistical significance. The subsequent cell apoptosis experiment revealed that after cells were transfected with miR-143 mimics, the cell apoptotic rate in the mimics group was significantly higher than that in the negative control group, with a statistically significant difference. To further determine the potential mechanism regarding miR-143 promotion of apoptosis of liver carcinoma cells, we assayed the signal transduction pathway of NF- $\kappa \mathrm{B}$.

The $\mathrm{NF}-\kappa \mathrm{B}$ signal transduction pathway is known to be involved in the development of various cancers including lung (18), colorectal (19) and liver cancers (20), in which it plays important roles. In the present study, we detected the protein and genetic expression of $\mathrm{NF}-\kappa \mathrm{B}$ in the mimics and the negative control groups, and the western blotting showed that after the expression of miR-143 in SMMC-7721 liver carcinoma cell line was upregulated, the protein and genetic

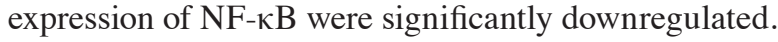

In conclusion, our results show that the upregulation in miR-143 expression in the SMMC-7721 liver carcinoma cell line can suppress the activity of $\mathrm{NF}-\kappa \mathrm{B}$ signal transduction pathway to a certain degree by inducing apoptosis of liver carcinoma cells, resulting in the significant inhibition of the cell proliferation rate. Since miRNAs can act on various target genes, the process in which miR-143 promotes apoptosis of liver carcinoma cells and inhibits the proliferation of liver carcinoma cells may be caused by the effect of other target genes, or the synergistic effect of several signal pathways. Thus, to clarify the mechanism regarding how miR-143 induces apoptosis of liver carcinoma cells requires in-depth investigation in future studies.

\section{Competing interests}

The authors declare that they have no competing interests.

\section{References}

1. Padhya KT, Marrero JA and Singal AG: Recent advances in the treatment of hepatocellular carcinoma. Curr Opin Gastroenterol 29: 285-292, 2013

2. Groulx JF, Giroux V, Beauséjour M, Boudjadi S, Basora N Carrier JC and Beaulieu JF: Integrin $\alpha 6 \mathrm{~A}$ splice variant regulates proliferation and the $\mathrm{Wnt} / \beta$-catenin pathway in human colorectal cancer cells. Carcinogenesis 35: 1217-1227, 2014.

3. Paul I, Bhattacharya S, Chatterjee A and Ghosh MK: Current understanding on EGFR and Wnt/ $\beta$-catenin signaling in glioma and their possible crosstalk. Genes Cancer 4: 427-446, 2013.

4. Chen P, Zhao X and Ma L: Downregulation of microRNA-100 correlates with tumor progression and poor prognosis in hepatocellular carcinoma. Mol Cell Biochem 383: 49-58, 2013.

5. Cheung TH, Man KN, Yu MY, Yim SF, Siu NS, Lo KW, Doran G, Wong RR, Wang VW, Smith DI, et al: Dysregulated microRNAs in the pathogenesis and progression of cervical neoplasm. Cell Cycle 11: 2876-2884, 2012.

6. Bae HJ, Jung KH, Eun JW, Shen Q, Kim HS, Park SJ, Shin WC, Yang HD, Park WS, Lee JY, et al: MicroRNA-221 governs tumor suppressor HDAC6 to potentiate malignant progression of liver cancer. J Hepatol 63: 408-419, 2015.

7. Bai JW, Xue HZ and Zhang C: Down-regulation of microRNA-143 is associated with colorectal cancer progression. Eur Rev Med Pharmacol Sci 20: 4682-4687, 2016.

8. Zhang HB, Sun LC, Ling L, Cong LH and Lian R: miR-143 suppresses the proliferation of NSCLC cells by inhibiting the epidermal growth factor receptor. Exp Ther Med 12: 1795-1802, 2016. 
9. Mao Y, Liu J, Zhang D and Li B: miR-143 inhibits tumor progression by targeting FAM83F in esophageal squamous cell carcinoma. Tumour Biol 37: 9009-9022, 2016.

10. Johannessen C, Moi L, Kiselev Y, Pedersen MI, Dalen SM, Braaten T and Busund LT: Expression and function of the miR-143/145 cluster in vitro and in vivo in human breast cancer. PLoS One 12: e0186658, 2017.

11. Zhang Y, Takahashi S, Tasaka A, Yoshima T, Ochi H and Chayama K: Involvement of microRNA-224 in cell proliferation, migration, invasion, and anti-apoptosis in hepatocellular carcinoma. J Gastroenterol Hepatol 28: 565-575, 2013.

12. Huang FT, Peng JF, Cheng WJ, Zhuang YY, Wang LY, Li CQ, Tang J, Chen WY, Li YH and Zhang SN: miR-143 targeting TAK1 attenuates pancreatic ductal adenocarcinoma progression via MAPK and NF- $\kappa B$ pathway in vitro. Dig Dis Sci 62: 944-957, 2017.

13. Zhao N, Wang R, Zhou L, Zhu Y, Gong J and Zhuang SM: MicroRNA-26b suppresses the NF- $\kappa$ B signaling and enhances the chemosensitivity of hepatocellular carcinoma cells by targeting TAK1 and TAB3. Mol Cancer 13: 35, 2014.

14. Khafaei M, Samie S, Mowla SJ, Alvanegh AG, Mirzaei B, Chavoshei S, Dorraj GS, Esmailnejad M, Tavallaie M and Nourani M: Evaluation of miR-9 and miR-143 expression in urine specimens of sulfur mustard exposed patients. Interdiscip Toxicol 8: 169-174, 2015.

15. Deftereos G, Corrie SR, Feng Q, Morihara J, Stern J, Hawes SE and Kiviat NB: Expression of mir-21 and mir-143 in cervical specimens ranging from histologically normal through to invasive cervical cancer. PLoS One 6: e28423, 2011.
16. Xu B, Niu X, Zhang X, Tao J, Wu D, Wang Z, Li P, Zhang W, Wu H, Feng N, et al: miR-143 decreases prostate cancer cells proliferation and migration and enhances their sensitivity to docetaxel through suppression of KRAS. Mol Cell Biochem 350: 207-213, 2011.

17. Borralho PM, Simões AE, Gomes SE, Lima RT, Carvalho T, Ferreira DM, Vasconcelos MH, Castro RE and Rodrigues CM: miR-143 overexpression impairs growth of human colon carcinoma xenografts in mice with induction of apoptosis and inhibition of proliferation. PLoS One 6: e23787, 2011.

18. He J, Qian X, Carpenter R, Xu Q, Wang L, Qi Y, Wang ZX, Liu LZ and Jiang BH: Repression of miR-143 mediates Cr (VI)-induced tumor angiogenesis via IGF-IR/IRS1/ERK/IL-8 pathway. Toxicol Sci 134: 26-38, 2013.

19. Szele E, Gombos K, Juhász K, Wohler V, Kovács A and Ember I: Effects of purified glycerol from biodiesel on miRNAs compared to the expression profile of selected mRNAs in Balb/c mice. In Vivo 27: 107-111, 2013.

20. Mosquera JM, Sboner A, Zhang L, Chen CL, Sung YS, Chen HW, Agaram NP, Briskin D, Basha BM, Singer S, et al: Novel MIR143-NOTCH fusions in benign and malignant glomus tumors. Genes Chromosomes Cancer 52: 1075-1087, 2013.

This work is licensed under a Creative Commons Attribution-NonCommercial-NoDerivatives 4.0 International (CC BY-NC-ND 4.0) License. 